\title{
KHẢO SÁT NỒNG Độ HORMONE TUYẾN CÂ̂N GIÁP Ở BỆNH NHÂN BỆNH THÂ̂N MẠN LỌC MÁU CHU KỲ TẠI BỆNH VIỆN HỮU NGHI! ĐA KHOA NGHỆ AN
}

\section{TÓM TẮT}

Bệnh nhân suy thận giai đoạn cuối phải lọc máu chu kỳ có rất nhiều các biến đổi về các chất như canxi, phospho và đăc biêt có tình trang cường tuyến cận giáp làm tăng nồng độ hormone tuyến cận giáp PTH (Parathyroid hormone). Muc tiêu: khảo sát nông độ hormone tuyến cận giáp ở bệnh nhân suy thận man loc máu chu kỳ. Đối tương và phương pháp nghiên cứu: Nghiên cứu mô tả cắt ngang tất cả 80 bệnh nhân được chẩn đoán suy thận giai đoạn cuối có eǴFR (mức lọc cầu thận ước tính) < $15 \mathrm{ml} / \mathrm{ph} / 1,73 \mathrm{~m}^{2}$ được lọc máu chu kỳ, thời gian từ tháng 1/2021 6/2021, tại Bệnh viện hữu nghị đa khoa Nghệ An. Kết quả: Tuổi trung bình là $50,31 \pm 17,031$ tuổi, trong đó tuổi thấp nhất là 17 và cao nhất 93 tuổi. Nam có 49 bệnh nhân chiếm tỷ lệ $61,3 \%$ và 31 bệnh nhân nữ chiếm tỷ lệ $38,7 \%$. Đa số bệnh nhân có thiếu máu $(88,8 \%)$. Mức lọc câu thận trung bình $13,42 \pm 9,03$ $\mathrm{ml} / \mathrm{ph} / 1,73 \mathrm{~m}^{2}$. Nồng độ canxi máu là $2,12 \pm 0,29$ $\mathrm{mmol} / \mathrm{l}$ và $\mathrm{PTH}$ là $569,06 \pm 608,19 \mathrm{pg} / \mathrm{ml}$. Tỷ lệ tăng nồng độ hormone PTH là $57,4 \%$ và PTH trong giới hạn bình thường chiếm $21,3 \%$. Tỷ lệ giảm canxi máu là $37,5 \%$. Có mối tương quan nghich có ý nghĩa thống kê giữa nồng độ hormone PTH với eGFR $(r=-0,409$; $p<0,05)$. Kết luân: Cường cân giáp thứ phát thường gặp ở những bệnh nhân chạy thận nhân tạo chu kỳ và tăng lên theo sự suy giảm của mức loc câu thân.

Tư khóa: Bệnh thận mạn, Lọc máu chu kỳ, PTH.

\section{SUMMARY}

\section{SURVEY OF PARATHYROID HORMONE} LEVELS IN PATIENTS WITH CHRONIC KIDNEY DISEASE ON DIALYSIS AT NGHE AN GENERAL FREINDSHIP HOSPITAL

End stage chronic kidney disease (ECKD) has many changes in substances such as calcium, phosphorus and especially hyperparathyroidism, which increases the level of parathyroid hormone (PTH). Objective: to investigate parathyroid hormone levels in patients with chronic renal failure on dialysis. Subjects and methods: A cross-sectional descriptive study. Total 80 participating patients diagnosed with ECKD with eGFR (estimated glomerular filtration rate) < 15 $\mathrm{ml} / \mathrm{min} / 1.73 \mathrm{~m}^{2}$ undergoing dialysis period, from January 2021 to June 2021, at Nghe An General freindship Hospital. Results: The mean age was $50.31 \pm 17,031$ years old, in which the lowest age was

*Bệnh viện hữu nghị đa khoa Nghệ An Chiu trách nhiêm chính: Ngô Đức Kỷ

Email: ngoduckyna@gmail.com

Ngày nhận bài: 22.6.2021

Ngày phản biên khoa họ: 19.8.2021

Ngày duyệt bài: 26.8.2021
Ngô Đức Kÿ*

17 years old and the highest age was 93 years old. There were 49 male patients, $61.3 \%$, and 31 female patients, $38.7 \%$. Most of the patients had anemia $(88.8 \%)$. eGFR was $13.42 \pm 9.03 \mathrm{ml} / \mathrm{min} / 1.73 \mathrm{~m}^{2}$. Blood calcium concentration was $2.12 \pm 0.29 \mathrm{mmol} / \mathrm{l}$ and PTH was $569.06 \pm 608.19 \mathrm{pg} / \mathrm{ml}$. The rate of increase in PTH hormone levels was $57.4 \%$ and PTH within normal limits accounted for $21.3 \%$. The rate of hypocalcemia was $37.5 \%$. There was a statistically significant negative correlation between PTH hormone levels and eGFR ( $r=-0.409 ; p<0.05)$. Conclusion: Secondary hyperparathyroidism is common in hemodialysis patients and increases with the decline of eGFR.

Keywords. Chronic kidney disease, dialysis, PTH.

\section{I. ĐĂT VẤN ĐỀ}

Bênh thân man (BTM) hiên nay là môt vấn đề sức khỏe của toàn cầu, ảnh hưởng đến $5-10 \%$ dân số thế giới, là hậu quả cuối cùng của nhiều bênh thân, diến tiến kéo dài qua nhiều năm tháng làm giảm mức lọc cầu thận một cách từ từ và không hồi phục, gây ảnh hưởng đến chất lượng, tỷ lệ sống còn của bệnh nhân và làm tiêu tốn ngân sách y tế của nhiều quốc gia [1]. Bệnh nhân bi bênh thân man giai đoan cuối sẽ có nhiều các biến chứng như bệnh lí tim mạch, tăng huyết áp, rối loạn lipid máu, loạn dương xương do thận,... và biện pháp cuối cùng điều trị là lọc máu chu kỳ hoặc ghép thận. ở bệnh nhân suy thận giai đoạn cuối phải lọc máu có rất nhiều các biến đổi về các chất như canxi, phốt pho và đặc biệt có tình trạng cường tuyến cận giáp làm tăng nồng độ hormone tuyến cận giáp PTH (Parathyroid hormone)[2]. Phát hiện và điều chỉnh sớm các rối loạn cân bằng Ca-P-PTH giúp cải thiện các triệu chứng tăng urê huyết, làm chậm diễn tiến của suy thận mạn và làm giảm nguy cơ tử vong do các biến chứng tim mach và loạn dưỡng xương do thận của cường tuyến cận giáp thứ phát. Trên thế giới đã có nhiều nghiên cứu về rối loan $\mathrm{Ca}$, Phospho, PTH. Ở Viêt Nam đã có các nghiên cứu về rối loạn $\mathrm{Ca}$, Phospho, PTH ở bệnh nhân bệnh thận mạn giai đoạn cuối [3],[4],[5], nhưng tại khu vực Nghệ An chưa có nghiên cứu đánh giá về các rối loạn này. Vì vậy, tôi tiến hành nghiên cứu đề tài này với mục đích: khảo sát nồng độ hormone tuyến cận giáp ở bệnh nhân suy thận mạn lọc máu chu kỳ để phát hiện sớm các rối loạn về chức năng tuyến cận giáp. 


\section{II. ĐỐI TƯỢNG VÀ PHƯƠNG PHÁP NGHIÊN CỨU}

Đối tượng nghiên cứu: Tất cả 80 bệnh nhân được chẩn đoán suy thận giai đoạn cuối có eGFR (mức lọc cầu thận ước tính) < 15 $\mathrm{ml} / \mathrm{ph} / 1,73 \mathrm{~m}^{2}$ được lọc máu chu kỳ, thời gian từ tháng 1/2021 - 6/2021, tại Bệnh viện hữu nghị đa khoa Nghệ An.

\section{Tiêu chuẩn loại trừ:}

- Bệnh nhân suy thận cấp, đang trong tình trạng viêm hoặc nhiềm trùng khác.

- Bệnh lý tuyến giáp - tuyến cận giáp.

- Bệnh nhân sử dụng các chế phẩm ảnh hưởng đến chu chuyển xương trong vòng 1 tháng trở lại đây.

- Bệnh nhân bệnh thận mạn giai đoạn cuối với các bệnh lí gan mật, men gan tăng.

- Ung thư di căn xương, bệnh lý xương khớp.

- Bệnh nhân không đồng ý tham gia nghiên cứu.

Phương pháp nghiên cứu: mô tả cắt ngang, cõ̃ mẫu thuận tiện.

-Thu thập số liệu theo mẫu bệnh án thống nhất, khai thác và khám lâm sàng: giới tính, tuổi, đo huyết áp, BMI. Các xét nghiệm công thức máu, glucose, ure, cretinin, acid uric, lipid máu, GOT, GPT, Điện giải đồ, Canxi và PTH máu.

-Xét nghiệm PTH bằng máy Cobas 6000 của hãng Roche, nguyên lý miễn dịch điện hóa phát quang theo nguyên tắc Sandwich.

-Tiêu chuẩn đánh giá trong nghiên cứu: sử dụng tiêu chuẩn của KDIGO 2012 về nồng độ Ca, PTH cần đạt của bệnh nhân bệnh thận mạn giai đoạn cuối trong nghiên cứu [1].

Số liệu được xử lý bằng phần mềm SPSS 20.11.

\section{KẾT QUẢ NGHIÊN CỨU}

\section{1.Đặc điểm chung nhóm nghiên cứu}

Bảng 1. Đặc điểm lầm sàng

\begin{tabular}{|c|c|c|}
\hline \multicolumn{2}{|c|}{ Đặc điểm } & Giá trị \\
\hline \multirow{2}{*}{ Giới } & Nam & $61,3 \%$ \\
\cline { 2 - 3 } & Nữ & $38,7 \%$ \\
\hline \multirow{3}{*}{ Tuổi (năm) } & Chung & $50,31 \pm 17,031$ \\
\cline { 2 - 3 } & Nam & $52,24 \pm 18,307$ \\
\cline { 2 - 3 } & Nữ & $47,26 \pm 14,55$ \\
\hline \multirow{4}{*}{ BMI (kg/m²) } & Chung & $20,6 \pm 2,0$ \\
\cline { 2 - 3 } & Nam & $20,9 \pm 2,1$ \\
\cline { 2 - 3 } & Nữ & $20,2 \pm 1,7$ \\
\cline { 2 - 3 } & $<18,5$ & $17,3 \%$ \\
\cline { 2 - 3 } & $18,5-22,9$ & $73,1 \%$ \\
\cline { 2 - 3 } & $\geq 23$ & $9,6 \%$ \\
\hline Huyết áp tâm thu & & $137,9 \pm 24,1$ \\
\hline (mmHg) & & $81,7 \pm 8,7$ \\
\hline $\begin{array}{c}\text { Huyết áp tâm } \\
\text { trương (mmHg) }\end{array}$ & & $70 \%$ \\
\hline Phù & & \multicolumn{2}{|c}{} \\
\hline
\end{tabular}

\begin{tabular}{|c|c|}
\hline Khó thở & $43,8 \%$ \\
\hline Suy tim & $41,3 \%$ \\
\hline Thiễu máu & $88,8 \%$ \\
\hline
\end{tabular}

Nhận xét: có 49 bệnh nhân nam chiếm tỷ lệ $61,3 \%$ và 31 bệnh nhẩn nữ chiếm tỷ lệ $38,7 \%$.

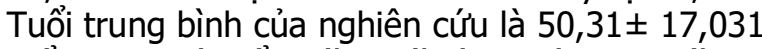
tuổi trong đó tuổi thấp nhất là 17 và cao nhất 93 tuổi. Đa số bệnh nhân có BMI ở giới hạn bình thường $(73,1 \%)$ và lâm sàng có thiếu máu $(88,8 \%)$.

Bảng 2. Đặc điểm cận lâm sàng

\begin{tabular}{|c|c|}
\hline Chỉ số & Giá trị \\
\hline Hồng câu $(\mathrm{T} / \mathrm{l})$ & $3,2 \pm 0,5$ \\
\hline $\mathrm{Hb}(\mathrm{g} / \mathrm{l})$ & $90,8 \pm 21,1$ \\
\hline $\mathrm{HCT}(\mathrm{g} / \mathrm{l})$ & $0,27 \pm 0,04$ \\
\hline $\mathrm{BC}(\mathrm{G} / \mathrm{l})$ & $7,4 \pm 3,3$ \\
\hline $\mathrm{TC}(\mathrm{T} / \mathrm{l})$ & $202,2 \pm 74,7$ \\
\hline Glucose $(\mathrm{mmol} / \mathrm{l})$ & $7,0 \pm 2,3$ \\
\hline Ure $(\mathrm{mmol} / \mathrm{l})$ & $23,7 \pm 9,6$ \\
\hline Creatinin $(\mu \mathrm{mol} / \mathrm{l})$ & $808,2 \pm 324,5$ \\
\hline Acid uric $(\mu \mathrm{mol} / \mathrm{l})$ & $496,4 \pm 122,4$ \\
\hline Albumin $(\mathrm{g} / \mathrm{l})$ & $43,7 \pm 48,2$ \\
\hline eGFR $\left(\mathrm{ml} / \mathrm{ph} / 1,73 \mathrm{~m}^{2}\right)$ & $13,42 \pm 9,03$ \\
\hline Ca $(\mathrm{mmo} / \mathrm{l})$ & $2,12 \pm 0,29$ \\
\hline PTH $(\mathrm{pg} / \mathrm{ml})$ & $569,06 \pm 608,19$ \\
\hline
\end{tabular}

Nhận xét: Trung bình số lượng hồng cầu là $3,2 \pm 0,5 \mathrm{~T} / \mathrm{l}$ và hemoglobin là $90,8 \pm 21,1 \mathrm{~g} / \mathrm{l}$. Mức lọc câu thận trung bình 13,42 $\pm 9,03$ $\mathrm{ml} / \mathrm{ph} / 1,73 \mathrm{~m}^{2}$. Nồng độ canxi máu là $2,12 \pm$ $0,29 \mathrm{mmol} / \mathrm{l}$ và PTH là $569,06 \pm 608,19 \mathrm{pg} / \mathrm{ml}$.

3.2.Mối liên quan giứa nồng độ hormone PTH và mức lọc câu thận (eGFR)

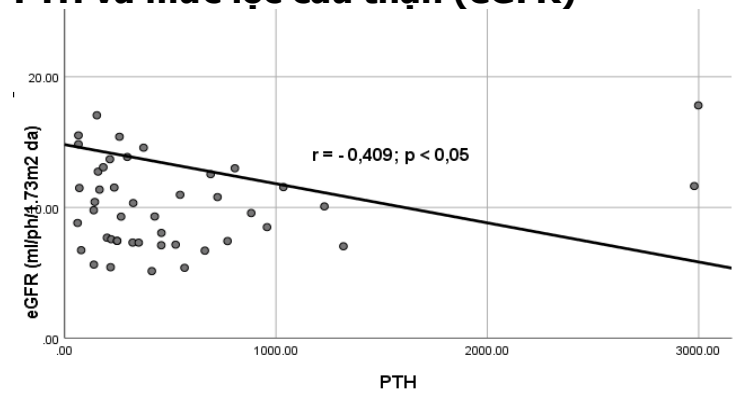

Biểu đồ 1. Mối liên quan giữa PTH và eGFR

Nhận xét: có mối tương quan nghịch có ý nghĩa thống kê giữa nồng độ hormone $\mathrm{PTH}$ và eGFR $(r=-0,409 ; p<0,05)$.

3.3. Tỷ lệ thay đổi nồng độ PTH và canxi máu

Bảng 3.Tý lệ thay đổi nồng độ PTH và canxi máu

\begin{tabular}{|c|c|c|c|}
\hline \multicolumn{2}{|c|}{ Giá trị } & Tân suất (n) & Tỷ lệ (\%) \\
\hline \multirow{3}{*}{ PTH } & $<150$ & 17 & 21,3 \\
\cline { 2 - 4 } & $150-300$ & 17 & 21,3 \\
\cline { 2 - 4 } & $>300$ & 46 & 57,4 \\
\hline \multirow{3}{*}{ Canxi } & $<2,1$ & 30 & 37,5 \\
\cline { 2 - 4 } & $2,1-2,5$ & 40 & 50 \\
\cline { 2 - 4 } & $>2,5$ & 10 & 12,5 \\
\hline
\end{tabular}


Nhận xét: Có 46 bệnh nhân tăng nồng độ hormone PTH chiếm tỷ lệ $57,4 \%$ và 17 bệnh nhân có PTH trong giới hạn bình thường chiếm $21,3 \%$. Có 30 bệnh nhân giảm canxi máu chiếm tỷ lệ 37,5\%.

\section{BÀN LUẬN}

Tuổi trung bình của nghiên cứu là 50,31 \pm 17,031 tuổi trong đó tuổi thấp nhất là 17 và cao nhất 93 tuổi. Tỷ lệ nam chiếm tỷ lệ $61,3 \%$ và bệnh nhân nữ chiểm tỷ lệ 38,7\%. Không có sự khác biệt về tuổi giữa nam và nữ giới. Tác giá Nguyễn Minh Tuấn [4], là 51,55 $\pm 16,44$ tuổi, trong đó nhóm bệnh nhân nữ có tuổi trung bình cao hơn nam giới tuy nhiên không khác biệt có ý nghĩa thống kê. Tác giả Lê Thị Đan Thùy [5] nghiên cứu tại Bệnh viện nhân dân 115 , tuổi trung bình 49,16 $\pm 13,76$, lớn nhất là 82 tuổi, nhỏ nhất là 22 tuổi. Tương tự như vậy, các tác giả khác trong nước hay nước ngoài đề có độ tuổi xung quanh 50 tuổi [6],[7],[8],[9]. Trung bình chỉ số $B M I$ là $20,6 \mathrm{~kg} / \mathrm{m}^{2}$. Đa số bệnh nhân có BMI ở giới hạn bình thường $(73,1 \%)$ và lâm sàng có thiếu máu $(88,8 \%)$. Kết quả của chúng tôi cũng tương đồng như các nghiên cứu trong nước [4],[6],[7].

Sự thiếu hụt men 1a hydroxylase (của tế bào biểu mô ống thận) ở bệnh nhân bệnh thận mạn dẫn đến giảm tổng hợp 1,25 dihydroxy vitamin D, gây giảm hấp thu canxi từ ruột, hậu quả là giảm canxi trong máu. Nồng độ canxi toàn phần trung bình trong nghiên cứu này là $2,12 \pm 0,29$ $\mathrm{mmol} / \mathrm{l}$ và có tỷ lệ giảm canxi máu $(<2,1 \mathrm{mmol} / \mathrm{l})$ là $37,5 \%$. Kết quả này tương đương với tác giả Ana P năm 2017 trên 2507 bệnh nhân bệnh thận mạn, nồng độ canxi máu trung bình là 2,27 $\pm 0,15 \mathrm{mmol} / \mathrm{I}[10]$. Tuy nhiên thấp hơn so với một số công bố trong nước. Nghiên cứu của Nguyễn Hoàng Thanh Vân tại Huế năm 2015 cho kết quả là 2,40 $\pm 0,27 \mathrm{mmol} / \mathrm{l}$ [6]. Tác giả Lê Thị Thùy Đan năm 2019 tại Bệnh viện Bình Dân là $2,69 \pm 0,37 \mathrm{mmol} / \mathrm{l}$ [5]. Sự khác biệt này có thể do khác nhau về thời gian bị bệnh, thời gian lọc máu, phương pháp điều trị hoặc sự khác nhau về chế độ ăn, chế độ dinh dưỡng từng vùng miền.

Bệnh thận mạn đặc trưng bởi sự giảm số lượng nephron dẫn đển giảm chức năng nội tiết và bài tiết của thận. Chức năng bài tiết giảm, gây ứ các chất chuyển hóa có hại, toan chuyển hóa và tăng ứ đọng phospho máu. Điêu này gây suy dinh dưỡng, giảm đáp ứng của xương đối với vitamin $D$, hủy chất đệm của xương, hạ canxi máu và tăng chỉ số $\mathrm{Ca} \times \mathrm{P}$. Cuối cùng sẽ kích thích tế bào tuyến cận giáp tăng tiết PTH thứ phát. Tăng sản tuyến cận giáp là một biểu hiện chính của cường tuyến cận giáp thứ phát do thận, và một yếu tố quan trọng phản ánh độ nặng cũng như sự tiến triển của bệnh. Quá trình tăng sản PTH kéo dài, không kiểm soát làm tăng canxi máu, rối loạn chu chuyển xương với tăng quá trình hủy xương và viêm xương nang xơ. Trong nghiên cứu này, trung bình PTH 569,06 \pm $608,19 \mathrm{pg} / \mathrm{ml}$. Kết quả này cao hơn một số các nghiên cứu trong nước [3],[6],[7] hay Kirti A nghiên cứu 60 bệnh nhân bệnh thận giai đoạn cuối là $173,93 \pm 62,62 \mathrm{pg} / \mathrm{mL}$ nhưng thấp hởn tác giả Lê Thị Đan Thùy là $651,74 \pm 413,191 \mathrm{pg} / \mathrm{l}$ [5]. Khi so sánh về tỷ lệ tăng PTH, tỉ lệ tăng PTH là $57,4 \%$ và tỷ lệ PTH trong giới hạn bình thường là $21,3 \%$ tỷ. Kết quả của tôi tương đồng với Nguyển Minh Tuấn năm 2020 là 59,3\% [4]. Theo nghiên cứu của Waziri $B$ thì tỷ lệ tăng PTH là $49,3 \%$ và trong giới hạn bình thường là $26,1 \%$ [8]. Như vậy so với các nghiên cứu khác nhau của các tác giả trong và ngoài nước nồng độ và tỷ lệ tăng PTH có khác với nghiên cứu của tôi điều này có thể lý giải do đối tượng nghiên cứu khác nhau, số lượng mẫu nghiên cứu, chủng tộc, thời gian mắc bệnh, thời gian lọc máu chu kỳ, và điều kiện điều trị nội khoa bảo tồn khác nhau.

ở nghiên cứu này, chúng tôi tìm thấy mối tương quan nghịch giữa nồng độ PTH với mức lọc cầu thận $(r=-0,409 ; p<0,05)$. Kirti A năm 2017 cũng cho kết quả là có mối tương quan nghịch giữa nồng độ PTH với mức lọc cầu thận ( $\mathrm{p} \leq 0,001 ; r=-0,525)$. Choi SW nghiên cứu 9162 người cho kết luận nồng độ PTH giảm có ý nghĩa với tăng mức lọc cầu thận (eGRF) ở những người $\geq 50$ tuổi tại Hàn Quốc. Như vậy, nồng độ PTH có liên quan đến mức lọc cầu thận đặc diệt ở bệnh nhân bệnh thận mạn lọc máu chu ký.

\section{KẾT LUÂ̂N}

Cường cận giáp thứ phát thường gặp ở những bệnh nhân chạy thận nhân tạo chu kỳ và tăng lên theo sự suy giảm của mức lọc cầu thận.

\section{TÀI LIÊU THAM KHẢO}

1. KDIGO 2012, "Clinical practice guideline for the evaluation and management of chronic kidney disease", Kidney International Supplements, 3(1), pp. 19-62.

2. Pieter E, Jordi B and Pablo UT, "Parathyroid hormone metabolism and signaling in health and chronic kidney disease", Kidney International, 2016, 90: 1184-1190.

3. Nguyê̂n Duy Cường, Doãn Thị Nghĩa, "Nghiên cứu tình trang cường cận giáp trang thứ phát ở bệnh nhân thận nhân tạo chu kỳ tại Thái Binh", Y học thức hành (914) - Số 4/2014, Tr 19 -21.

4. Nguyển Minh Tuấn, "Nghiên cứu nồng độ osteoprogetin, parathyroid hormone huyết tương, 
tổn thương động mạch cành và một số yếu tố liên quan ở bệnh nhân bệnh thận mạn lọc máu chu kỳ", Luân án tiến sĩ, Trường đai họ Ỵ Dược Huế 2020.

5. Lề Thị Đan Thùy, Phạm Văn Bùi, "Khảo sát nồng độ canxi, phospho, hormone tuyến cânn giáp ở bệnh nhân bệnh thận mạn loc máu chu kỳ và lọc màng bụng liên tục ngoaii trú tại Bệnh viện Bình Dân", 2019, Y Học TP. Hồ Chí Minh, Phụ Bản Tập 23, Số 3, 2019, tr $234-240$.

6. Nguyê̂n Hoàng Thanh Vần, "Nghiên cứu nồng độ Beta-crosslaps, hormone tuyến cận giáp huyết thanh ở bênh nhân bệnh thận mạn giai đoạn cuối", Luận aán tiến sĩ, Trường đại học Y Dược Huế 2015.

7. Nguyển Hữu Vũ Quang, "Nghiên cứu nồng đô FGF-23 huyết thanh và môi liên quuan với một số rổi loạn khoáng xương ở bệnh nhân bệnh thận mạn", Luận án tiễn sĩ, Trường đại học Y Dược Huế 2020.

8. Waziri B, Duarte $\mathbf{R}$, Naicker $\mathbf{S}$, "Biochemical markers of mineral bone disorder in South African patients on maintenance haemodialysis", African Health Sciences Vol 17 Issue 2, June, 2017: 445 - 452.

9. Wang WH, Chen LW, Lee CC, et al, "Association between Parathyroid Hormone, $25(\mathrm{OH})$ Vitamin D, and Chronic Kidney Disease: A Population-Based Study", BioMed Research International, Volume 2017, Article ID 7435657, 9 pages.

10. Ana $\mathbf{P}$, Luís $\mathbf{S}$, Hugo GF, "The calcium/ phosphous homeostasis in chronic kidney disease: from clinical epidemiology to pathophysiology", Acta Med Port,2017, 30(6): 485-49.

\section{NGHIÊN CỨU ĐĂC ĐIỂM LÂM SÀNG VÀ KẾT QUẢ THANG ĐIỂM YMRS Ở BÊ̂NH NHÂN RỐI LOẠN LƯỠNG CỰC}

Đinh Việt Hùng 1

\section{TÓM TẮT}

Mục tiêu: Nghiên cứu đặc điểm lâm sàng rối loạn lưỡng cực bằng thang điểm YMRS. Đối tượng và phương pháp nghiên cứu: 51 bệnh nhân rối loạn lưỡng cực được điều trị nội trú tại Khoa Tâm thần, Bệnh viện Quân y 103. Kết quả: Hoang tưởng tự cao gặp nhiều nhất chiếm $84,21 \%$ và tăng khí sắc gặp 92,16\%. Có 88,24\% bệnh nhân tăng hoạt động và sự chi phối hành vi chiếm $71,05 \%$. Khi bệnh nhân vào viện thì điểm trung bình YMRS 34,18 \pm 11,25 điểm; sau 3 tuân điều trị thì điểm trung bình YMRS 13,63 \pm 5,74 điểm. Kết quả điều tri bệnh nhân dùng kết hợp olanzapin và encorate là 9,16 $\pm 2,94$ điểm. Kết luận: Lâm sàng ở bênh nhân rối loạn lưỡng cực rất đa dạng và phong phú. Thang điểm YMRS là một công cụ khách quan để đánh giá giá tri các triệu chứng lâm sàng của bệnh nhân rối loạn lưỡng cực.

Tư khóa: Rối loạn lưỡng cực, thang điểm YMRS

\section{SUMMARY}

STUDY CLINICAL FEATURES AND RESULT OF YMRSSCORE IN BIPOLAR DISORDER PATIENTS

Objective: To study clinical features of bipolar disorder patients by YMRS score. Method: The sample was composed by 51 bipolar disorder patients admitted as in-patients to Psychiatry Department, 103 Military Hospital. Results: Grandiose delusion and elevated mood are the most popular symptoms, accounting for $84.21 \%$ and $92.16 \%$ in sequence. There are $88.24 \%$ patients who had increased goaldirected activity and the number of patients whose behaviors had been controlled is $71.05 \%$. When the patients were admitted to the hospital, average YMRS

${ }^{1}$ Bênh viện Quân y 103-Học viện Quân y

Chịu trách nhiệm chính: Đinh Việt Hùng

Email: bshunga6@gmail.com

Ngày nhận bài: 24.6.2021

Ngày phản biên khoa hoc: 20.8.2021

Ngày duyệt băi: 26.8.2021 score was $34.18 \pm 11.25$ point and after 3 weeks of treatment, the score was $13.63 \pm 5.74$ point. In patients who were treated by olanzapin and encorate, the score was $9.16 \pm 2.94$ point. Conlusion: Clinical feartures in bipolar disorder patients are very diverse. YMRS score is objective tool to evaluate the worth of clinical symptoms of bipolar disorder patients

Key words. Bipolar disorder, YMRS score

\section{I. ĐĂT VẤN ĐỀ}

Rối loạn lưỡng cực là rối loạn tâm thân được đặc trưng bằng giai đoạn hưng cảm hoặc giai đoạn hưng cảm nhẹ, có phối hợp với giai đoạn trầm cảm trong quá trình phát triển của bệnh. Đây là rối loạn tâm thân nặng, bệnh sinh rất đa dạng và phức tạp gôm các yếu tố sinh học, yếu tố tâm lý, yếu tố môi trường và yếu tố nhân cách. Tỷ lệ mắc rối loạn lưỡng cực vào khoảng 0,4-1,6\% với các rối loạn lưỡng cực I, rối loạn lưỡng cực II, khí sắc chu kỳ và hưng cảm nhẹ. Đến nay, nghiên cứu về rối loạn lưỡng cực, đặc biệt là giai đoạn hưng cảm, mới chỉ dừng lại ở phân tích các đặc điểm lâm sàng. Chưa có nhiêu nghiên cứu đề cập kĩ về các thang điểm trong đánh giá lâm sàng. Để góp phân tìm hiểu kỹ hơn bệnh cảnh lâm sàng trong rối loạn lưỡng cực, chúng tôi tiến hành nghiên cứu đăc điểm lấm sàng và kết quả thang điểm YMRS ở bệnh nhân rối loạn lưỡng cực.

\section{II. ĐỐI TƯợNG VÀ PHƯƠNG PHÁP NGHIÊN CỨU}

2.1. Đối tượng nghiên cứu. Đối tượng nghiên cứu gồm 51 bệnh nhân đáp ứng đây đủ tiêu chuẩn chẩn đoán rối loạn lưỡng cực theo ICD-10 điều trị nội trú tại Khoa Tâm thần-Bệnh viện Quân y 103 từ tháng 5/2020 đến tháng 5/2021. 